\title{
Research on Inspection Testing and Certification Industry in China
}

\author{
Zhaoying Zuo', 2, a, Yuesheng Zhang 3, b, Luogao Wang, b, Jian Sun', b, Na Li, b \\ ${ }^{1}$ School of Business, Hohai University, Nanjing, 210000, China; \\ ${ }^{2}$ Rizhao Inspection \&Certification Co., Ltd Rizhao, 276800, China; \\ ${ }^{3}$ Rizhao entry-exit inspection and quarantine bureau, 276800, China. \\ azuozhaoying0531@sina.com, brzccic@126.com
}

\begin{abstract}
The paper analysis the present situation of inspection testing\& certification industry in China. Then propose some measures should be taken to enhance the international competitiveness of the industry. Firstly, reforming management mode and accelerating the process of internationalization. Secondly streamlining government functions and administration. Thirdly promoting regulation in process and afterward and strengthen the system construction.
\end{abstract}

Keywords: Inspection testing \& certification; Enhance the international competitiveness; Reform management mode; System construction.

\section{检验检测认证行业发展研究}

\author{
左兆迎 ${ }^{1,2}$, 张岳胜 ${ }^{3}$, 王洛高 ${ }^{3}$, 孙健 ${ }^{2}$, 李娜 ${ }^{2}$ \\ 1. 河海大学商学院, 南京 中国; \\ 2. 日照检验检疫局, 日照 中国; \\ 3. 日照检验认证公司, 日照 中国
}

摘 要: 在总结检验检测认证行业现状基础上, 从创新管理模式及加快国际化进程、简政放权 及加强事中事后监管、加强制度建设, 实行多元共治等方面分别对检验检测认证行业发展及 提升行业国际竞争力提出了发展建议，对于理论研究和实践都有较好的参考价值。

关键词：检验检测认证；简政放权；事中事后监管；多元共治

\section{1. 前言}

检验检测认证既是国家质量基础和国家创新体系的重要组成部分, 也是现代服务业的重要 组成部分, 先后被国务院列为重点发展的 8 大高技术服务业和 11 大生产性服务业之一。现有 文献大部分单独从认证监管角度[1-5]或者检验检测监管角度 $[6,7]$ 单独来展开叙述, 仅有个别 文献[8]将检验检测认证作为一个行业来论述，但是论述不够深入。

\section{2. 我国检验检测认证行业现状及存在的问题}

我国检验认证市场规模 2013 年超过 1000 亿元，已成为仅次于美国、欧元区的第三大检验 认证市场, 到 2020 年有望超过 2500 亿元。近年来中国的认证业务每年 $10 \%$ 左右递增, 2015 年认证机构颁发的现行有效认证证书 147.9 万余张, 和 2014 年相比增长了 $13.8 \%$ 。2015 年检 验检测的市场规模稳步提高, 全国检验检测机构总数超过 3.1 万家, 与 2014 年相比增长了 $9.82 \%$, 营业收入达 1799.98 亿元, 比去年全年增加 $10.37 \%$, 远高于全国国内 GDP 生产总值。 全国认证机构总数为 218 家，年营业收入在 220 亿元左右。

(1) 小、散是目前国内检验检测认证机构存在的普遍状况。年报显示 SGS、Intertek、BV 2014 年收入分别为人民币 425 亿、201 亿、289 亿, 而我国最大的检验认证集团收入不超过 100 亿 
元,获得资质认定的 100 余家外资检验检测机构所占有的市场份额已经接近整个市场的 30\%。 有的部门直属检验检测认证机构就有 70 多家, 有的地方同样是对水的检测环境、水利、农业、 卫生、质检、食药、国土、住建等部门均承担了检测职责，市场分割严重，由于国有检测机 构分属不同的地区和部门, 每个机构为了生存都会采取各种行政干预的方式来阻碍其他质量 技术机构进入到本地区或本行业以保证自己的垄断地位。

(2)技术实力和品牌影响力有待进一步提高。 2015 年中国从朝鲜进口无烟煤 70 余万吨, 朝 鲜供货商选择的几乎都是 SGS、Intertek 等外资检验机构进行检验用于贸易结算。中国 2015 年进口镍矿 3500 余万吨, 九成以上采用外资检验机构进行检验。除此之外, 巴西淡水河谷、 必和必拓等矿山皆倾向于采用外资检验机构进行保护性检验。我国虽然在世界上颁发认证证 书数量最多, 但对国际上出现的认证认可新领域、新技术, 我国基本处于跟踪研究阶段, 被 动接受欧美评价标准与制度, 如对于 IFS、BRC 等认证在国内几近被外资认证机构所垄断, 而我国监管部门对于 BRC 等认证项目尚不具备认可的资质。

(3) 监管部门亟待进一步提升监管水平。由于检验有一定的技术性, 对于检验结果出现异 议一般都另请一家第三方检验机构进行检验, 对于因检验因出现问题的检验机构受到处罚的 少之又少, 起不到应有的震慑作用, 不利用行业的健康发展。此外对于外资检验机构监管不 够到位, 有的检验机构接受海外进口大宗散货产品检验时, 不具备相应检验条件甚至不登轮 编造检验结果, 扰乱了进出口商品检验秩序, 对于该类现象应严加查处并加以公开通报。对 于认证业务, 应在立足于抽查人天数的同时加强对认证机构现场工作有效性的监督检查, 查 看是否给不具备认证条件的企业通过了认证, 经过调查发现半数以上的中小企业获取认证证 书的目的是下游客户或者供货商的要求, 他们的实际工作可能未按照体系要求去执行, 达不 到认证所需要的要求。

(4)国家经费投入不足。德国的标准对 GDP 的贡献率为 $0.9 \%$, 法国和澳大利亚为 $0.8 \%$; 欧盟的计量技术成本收益比为 2.7 , 德国为 3.9, 荷兰为 3.6。我国检验检测对 GDP 的贡献率 为 $0.1 \%$, 认证认可对国民经济和社会发展的贡献率分别为 $0.914 \%$ 和 $0.338 \%$ 。在新能源、新 材料、新一代信息技术等新兴产业领域，认证认可技术体系还基本处于空白状态；在服务业 领域, 服务认证的覆盖范围与技术水平明显滞后于服务业大发展的趋势。美国国家标准与技 术研究院负责美国政府各部门的标准化政策, 2013 年获得美国政府的拨款高达 7.69 亿美元, 我国负责国家质量基础建设研究的中国标准化研究院、中国计量科学研究院、中国检验检疫 科学研究院等一年的经费一共不到 7 亿元。

\section{3. 检验检测认行业发展的战略选择}

\section{1 创新管理模式, 加快国际化进程}

第一, 创新管理模式, 释放改革红利。尝试进行公务员制度改革, 可以学习江苏、浙江等 地聘任制公务员的管理模式, 积极引进具有全球市场、丰富管理经验的海内外高层次人才进 监管部门重要岗位工作; 尝试推进行业外独立监管制度, 可以借鉴美国注册会计师等行业的 行业外独立监管制度, 克服行业协会监督不够透明和政府监管效率不高的缺点; 强化检验检 测认证的法律地位, 如关于清真认证, 现在的趋势是各国都开始把清真食品认证纳入到国家 的法律体系中, 约旦、沙特、马来西亚、新西兰相继把原来的企业认证收归为国家认证。中 共中央、国务院《关于深化国有企业改革的指导意见》明确提出国有企业分为商业类和公益 类两类, 可以探索推进检验检测认证机构分类改革, 将部分检验检测认证纳入公益类国有企 业。引导和扶持优秀的检验检测认证企业进行上市融资, 创造条件实现集团公司整体上市, 为国有检验检测认证企业进行混合所有制改革保驾护航，鼓励非国有资本投资主体通过出资 入股、收购股权、认购可转债、股权置换等多种方式, 参与国有检验检测认证企业改革, 鼓 励国有资本以多种方式入股非国有检验检测认证企业, 鼓励检验检测认证机构形成产业集群 及产业联盟; 
第二，加快检验检测认证机构的兼并重组。国办发〔2014〕8 号文件明确指出“进一步理顺 政府与市场的关系, 科学界定国有检验检测认证机构功能定位, 大力推进整合, 优化布局结 构, 创新体制机制, 转变发展方式, 不断提升市场竞争力和国际影响力, 推动检验检测认证 高技术服务业做强做大。”积极推进整合重组, 发挥并购后的协同效应是提核心竞争力的重要 举措之一，抓住“中国制造 2025”、“一带一路”建设难得的历史机遇，为检验检测认证行业的 发展打开空间。国外大型综合性检测机构近年来在全球范围内展开了较大规模的收购兼并, 迅速进入了新的市场, 在短时间内获得资质、渠道和人才, 我们应当学习海外检验机构的发展 模式, 在大力推进国内检验检测认证机构重组, 推动检验检测去部门化, 消除行业分割。

第三，提升国际化水平。研究建立统一的检验检测机构资质认定制度，积极支持国内检验 检测机构走出国门, 在财政、税收等方面进行减免; 引导检验检测机构和认证机构做到检验 检测业务和认证业务的有机结合相互补充, 为企业提供全产业链的跟踪服务; 需要提高我国 认证认可自主创新能力, 争取率先在国际上提出先进的评价标准与评价方法。可以学习国外 的一些做法如澳大利亚和新西兰两国,联合起来搞体系认证,成立联合的体系认证认可机构; 英 国和荷兰也将审核员培训、注册以及体系认证(注册)机构的认可向国外开放,形成一个准国际 性认可机构; 欧盟自世纪年代以来，与美国、加拿大、澳大利亚、新西兰、瑞士、以色列、 日本等国家达成了很多双边互认协议, 对出口起到了很大的促进作用。我国也可以借鉴这些 国家的经验，积极地深化港澳台认证认可合作机制以及与他国建立互认机制。此外，还应加 大我国在国际标准制定中的参与比重, 掌握标准制定的话语权, 减少技术壁垒。

\section{2 简政放权, 加强事中事后监管}

第一, 加大政府购买服务力度, 优化检验检测认证市场发展环境。随着国家职能转变, 监 管部门的趋势是管办分离、管检分离, 具体业务会交给社会中介去做。各级质检政府, 特别 是市、县这方面设备及能力参差不齐, 政府需要去委托和购买质量服务。学习推广上海、厦 门、天津、前海蛇口等自贸区的第三方检验采信经验, 将第三方采信的范围扩大到玩具、食 品等日常消费品。根据事中、事后监管评估结果, 可以对被采信机构实施周期评估、分类等 级动态调整以及暂停、取消采信资质等退出措施, 强化企业主体责任。同时加强国际交流, 学习国外采信的经验, 如法国、捷克和波兰政府除对产品安全领域的监管一般采用政府实验 室检测外，其他检测服务都通过对第三方检测结果予以采信的方式，对政府采信的第三方检 验检测认证机构建立完整的监管制度体系。通过第三方采信, 还可以使监管部门从繁杂的日 常事务中解脱出来, 做好事中事后的监管工作。

第二, 防范风险, 加强事中事后监管。对于食品、药品等高风险产品加强监管, 可以学习 美国的做法在销售产品时必须通过 GMP、GAP、HACCP 等一系列强制认证, 加强大数据与 电子商务在检验检测认证行业的应用, 健全事中事后监管机制, 汇总整合和关联分析有关数 据并构建大数据监管模式, 提升政府科学决策和风险预判能力。做好对检验检测认证机构有 效性、规范性的监督抽查, 针对突出问题和薄弱环节开展专项检查, 建立机构的诚信档案, 对于 检验检测领域制定机构评级分类标准, 通过调查客户满意度、公司治理、社会责任等指标定 量分析及综合评价, 为企业选择检验检测认证机构提供参考, 国家监管部门或行业协会可运 用评价指标体系及模型调查分析确定全国检验检测认证机构以及总体行业的有效性, 地方政 府主管部门或地方协会可运用本指标体系及模型调查分析确定本地区检验检测认证的有效 性。设立赔偿基金, 类似于银行的法定准备金, 由监管部门统一调配, 专款专用, 赔偿过程 等信息透明, 对有不良记录的第三方检验检测认证机构规定较高比例的数额, 对连续几年无 不良记录的检验检测认证机构规定较低比例的数额, 遇到重大质量问题可由监管部门出面进 行协调并直接用赔偿基金进行赔偿; 类似于建立证券市场的保荐人制度，加强对机构和从业 人员的监管, 形成终身信用跟踪制。

第三, 提升科研能力和科研水平。急需深入研究并建立新型服务认证理论与技术体系。学 习江苏省特种设备安全监督检验研究院集中精力搞科研出成果的做法, 推进系统内科研院所 的整合改革, 加强军民融合、“大飞机”工程、智能机器人和国家信息安全等重要领域的检验 
检测认证技术开发与研究; 推动检验检测服务与制造的深度融合, 加强在新型能源、低碳环 保和无线导航等方面检验检测水平, 通过建设医药检测平台等手段实现对生物医药、新材料 等领域全方位的检测和分析技术服务。加大对在基础研究、应用研究等方面有突破有创新人 才的奖励, 研究海上风电认证关键技术、生物质能认证关键技术、新能源汽车相关产品及材 料检测验证技术、太阳能利用产品与系统评价技术等前瞻性技术评价, 学习宜宾学院设立质 检学院的经验推进和一流院校、一流科研院所、工程技术中心及大型骨干企业研发中心的合 作。鼓励技术机构横向联合和产学研检用纵向联合, 加强和国际一流科研院所在人员互派等 方面的合作, 加强对国外新制定标准的研究和转化能力, 加快对市场有需求的标准的研发能 力及对先推出标准与传统标准之间的整合能力, 服务于国内企业, 如 BRC 认证开展了近 20 年目前更新到了第七版才有国内机构开始受理该业务, 给国内企业带来了不便的同时也削弱 了我国认证的地位。

\section{3 加强制度建设, 实行多元共治}

首先, 建立健全检验检测认证的社会诚信体系与制度建设。市场经济本质上是诚信经济和 制度经济, 要构建认证有效性的长效机制, 就必须不断完善市场经济体制, 建立健全符合我国国 情、与国际惯例接轨、适应现代市场经济发展的社会诚信体系; 监管部门要及时制定相关的 配套规章制度和规范性法律文件, 确立具有导向性的政策,加强对地方各级认证监管部门的认 证执法指导,完善督导检查制度,统一工作标准。

第二, 充分发挥行业协会的作用。检验检测认证行业内存在多个协会, 并且有的协会之间 界定不明晰, 并且和政府有着较为密切的联系, 削弱了协会的自律功能, 有必要对存在的行 业协会进行整合。2012 年, 我国质量检验检测行业市场规模为 850 亿元, 其中我国第三方检 测市场规模达到 383 亿元, 2013 年, 我国质量检验检测行业市场规模为 980 亿元, 其中第三 方检测市场规模达到 462 亿元。这么大的市场规模检验检测机构难免鱼龙混杂, 加强监管势 在必行, 应加大对超范围经营、篡改原始数据等违反行为的处罚措施并公开通报。充分发挥 协会在人员注册、培训开发、会员服务、自律监管、技术标准和开展国内外检验检测认证业 务交流合作等方面的作用, 严厉打击买证买证、违规经营、无证经营等行为。

第三, 充分发挥民间监督的作用。引进听证会制度, 鼓励公众参与到检验检测认证制度的 调整和改革中来, 增强工作的透明度; 对行业内媒体进行整合, 改革行业内媒体定位, 让百 姓深度参与媒体之中, 办成老百姓喜闻乐见的媒体, 在车站、码头随处都可以购买, 围绕检 验检测认证认可知识“下工厂、进社区、到课堂”, 研究针对不同层次受众的宣传方法, 分门 别类制作宣传材料, 开展检验检测认证科学普及试点示范。此外, 设立举报基金等方式调动 民间对检验检测认证机构违法违纪行为举报的积极性, 并对举报人实行严格的保密制, 完善 申诉、投诉处理制度和程序,对群众的投诉做到处理及时、按章办事度。

\section{4. 结论}

国家应从从创新管理模式及加快国际化进程、简政放权及加强事中事后监管、加强制度建 设及实行多元共治等方面着手更好促进检验检测认证行业的健康发展, 提升行业的国际竞争 力, 夯实国家质量基础。

\section{References}

[1] Huang Xin Tao Xiaoma Xing Jianwu. Analysis on Collusion-proof for Authentication Mechanism of Tradable Energy Saving Certificates [J]. Economic Management Journal, 2009(11).

[2] Castka P, Prajogo D, Sohal A, et al. Understanding firms壮 selection of their ISO 9000 third-party certifiers [J]. International Journal of Production Economics, 2015, 162:125-133. 
[3] Chen Yanying, Bao Zongke. Optimal Number Structure of Certification Industry in China under Exogenous Collective Reputation Constraints [J].Journal of Finance and Economics 2014 (8).

[4] Strausz R. Honest Certification and the Threat of Capture [J]. Discussion Paper, 2004, 23 (s $1-2): 45-62$.

[5] Friederike Albersmeier, Holger Schulze, Gabriele Jahn, Achim Spiller The reliability of third-party certification in the food chain: From checklists to risk-oriented auditing Food Control 2009 vol. 20,(10) 927-935,

[6] Li Lafang, Li Ximeng,He Jiang .Inspection testing service industry development strategy research in China of thirteenth five year plan Economic Review 2015(5):11-15

[7] Zhang Rongmei Supervision for the import and export commodity inspection appraisal organization work [J] China inspection and quarantine 2012(2)

[8] Jin Bei, Wang Yan-mei, Chen Xiao-dong.The Nature of Economics of Inspection and Certification and Its Industrial Regulation-Based on the Survey over Chinas Inspection and Certification Bodies [J]. Economic Management Journal in China, 2012(1). 